\title{
Analysis of Qiushui Lake Aquatic Products Cold Chain Logistics
}

\author{
Hao Dong, Tong Han \\ Beijing Wuzi University, Beijing, China \\ Email: 110156392@qq.com
}

How to cite this paper: Dong, $\mathrm{H}$. and Han, T. (2017) Analysis of Qiushui Lake Aquatic Products Cold Chain Logistics. Open Journal of Social Sciences, 5, 76-84. https://doi.org/10.4236/jss.2017.512006

Received: November 21, 2017

Accepted: December 10, 2017

Published: December 13, 2017

Copyright $\odot 2017$ by authors and Scientific Research Publishing Inc. This work is licensed under the Creative Commons Attribution International License (CC BY 4.0).

http://creativecommons.org/licenses/by/4.0/

\section{(c) (i) Open Access}

\begin{abstract}
A County is called China "crab village", Qiushui Lake is the main origin of A County crab. This paper focuses on the systematic analysis of the status and problems of Qiushui Lake aquatic products cold chain logistics, and finds out the countermeasures to improve the cold chain logistics of Qiushui Lake aquatic products. First of all, it analyzes the various factors that affect Qiushui Lake aquatic products cold chain logistics, which are the lack of relevant industry standards, the imperfect national laws and regulations, the shortage of cold chain logistics professional, the lack of third party cold chain logistics companies, the lack of network information technology effects of five factors on Qiushui Lake aquatic products cold chain logistics. And then it puts forward some suggestions to improve the development of Qiushui Lake cold chain logistics, such as perfecting relevant laws and regulations and industry standards, and speeding up the development of third party aquatic products cold chain logistics companies.
\end{abstract}

\section{Keywords}

Aquatic Product, Cold Chain Logistics, Logistics Professionals, Problems and Solutions

\section{An Overview of Related Issue}

\subsection{Cold Chain Logistics Development Background}

China's cold chain logistics started later, the initial development is slow. In recent years, with the rapid economic development in our country, with the improvement of living standards, people are paying more and more attention to the quality and freshness of agricultural products, aquatic products, dairy products, quick-frozen foods and others fast moving consumer goods, thus generating strong demand for cold chain logistics. At the same time, relevant government 
departments have also introduced some policies and measures to promote the development of cold chain logistics industry, China's cold chain logistics industry has entered a period of rapid development.

\subsection{The Concept of Cold Chain Logistics}

According to the expression of People's Republic of China National Standard Logistics Terminology, cold chain logistics refers to the frozen food in the production, storage, transportation, sales, until the consumer, in the process, the product is always in the prescribed low-temperature environment to ensure food quality and reduce food loss.

The flowchart shown in Figure 1 is currently a typical flow chart of the cold-chain logistics market in China. From this flowchart, it can be clearly seen that each element of the cold-chain logistics is interlocked and tightly connected. Cold chain logistics from suppliers to consumers almost every process is in the control of the temperature, This shows that the essential factor in cold chain logistics is the temperature, the temperature is effectively controlled determines the success or failure of the cold chain logistics.

\subsection{Aquatic Products Characteristics}

1) Our country has a vast ocean area, the Yangtze River and the Yellow River two major river basins and many natural lakes, aquatic products is very rich and the species is quite diverse, the same consumer demand for aquatic products also vary, so this created the consumer, hotel and aquatic retailers demand presents a variety, low-volume, fast circulation characteristics [1].

2) Aquatic products and other industrial products are different, Aquatic products are fresh, the vast majority of aquatic products in the form of refrigerated or frozen, customers have high demands on their color and freshness. In order to keep it fresh, it needs to be refrigerated, but the refrigerating time should not be too long, therefore, aquatic products need to reach consumers quickly after fishing.

3) Good packaging, contribute to the quality and safety of aquatic products. High moisture content of aquatic products, so at room temperature is also very easy decay and deterioration, affect their food safety. If the aquatic product is

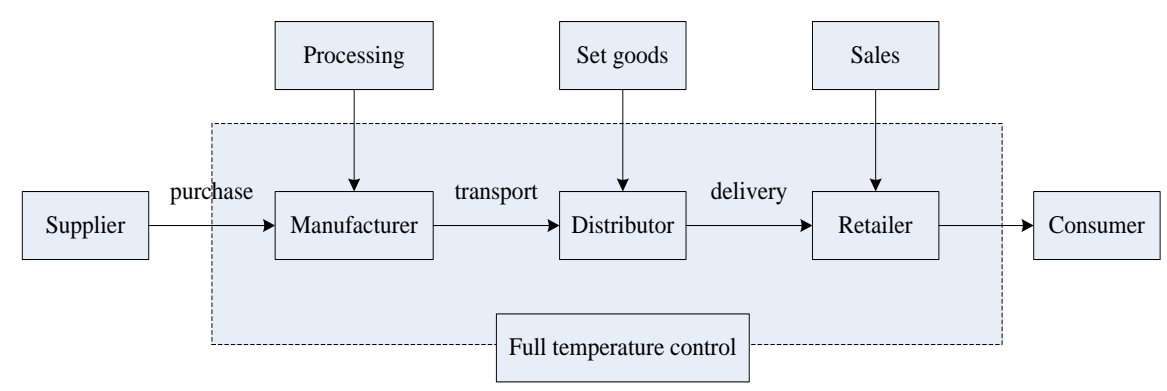

Figure 1. Refrigeration supply chain flow chart. 
not properly packaged, the aquatic product may deteriorate during its transportation and may even affect the quality and safety of other products.

\subsection{Cold Chain Logistics Characteristics}

As an important part of logistics, cold chain logistics not only has the characteristics of general logistics, but also has its own characteristics, such as strict requirements on refrigeration technology and time, which is the main difference between cold chain logistics and other logistics. In addition, the cold chain logistics also has the following characteristics: 1) large investment in construction and complex technology; 2) Higher coordination of all aspects of the cold chain; 3) Effective control of operating costs and cold chain development Closely related; 4) Cold chain logistics market is small in scale and network is fragmented.

\section{Development Status and Problems Analysis of Qiushui Lake Aquatic Products Cold Chain Logistics}

\subsection{Development Status}

\subsubsection{Qiushui Lake Aquatic Products Cold Chain Logistics Infrastructure Continues to Improve}

A county departments and educational institutions take a variety of ways to strengthen the professional management of aquatic products cold chain logistics and network information personnel, using a variety of forms of publicity universal knowledge of cold chain logistics knowledge, to encourage colleges and universities to open the course of cold chain logistics; Increase the policy of aquatic products cold-chain logistics investment; Speed up the implementation of standards for aquatic products cold chain logistics equipment and facilities; guide the integration of development. It provides a good basis for policies and regulations for the development of cold chain logistics in Qushui Lake.

A county industrial cluster planning a total area of 15.9 square kilometers, is one of 180 industrial clusters approved by the provincial people's government. At present, the dominant industry in the industrial clusters in A county is dominated by strong and rapid development momentum. A county's cooling industry strong and rapid development momentum. Has formed a refrigerated trucks, freezers, refrigerators as the leading product, with the ice bear refrigerated trucks, Xiang Xuehai, Siu Kong Electric, Matsukawa special vehicles and other equipment more than 20 companies. This provides a complete infrastructure for the development of Qushui Lake's cold chain logistics.

\subsubsection{Qiushui Lake Aquatic Product Market System Is Still in Its Infancy} In the background of the rapid development of the world's logistics, China's logistics industry started relatively late, let alone a professional aquatic cold chain logistics industry [2]. Farmers often suffer from traditional attitudes and spending habits, often on the sidelines of emerging things, and are reluctant to invest their money in an industry they see as risky, which has led them to think about cold Chain logistics such a sunrise industry is not valued. Similarly, at the national 
level, the logistics industry started late and did not fully understand the logistics. In addition, the logistics costs were usually calculated intentionally or unintentionally into other costs. Therefore, China's logistics-related policies are not perfect, which has become the main reason of the cold-chain logistics industry lack of effective management and monitoring.

Similarly, Qiuhu Lake aquatic products cold chain logistics market system will also be affected. Qiushui Lake aquatic products market framework layout lack of consideration. Uncoordinated market hardware and software facilities, aquatic products market system is still in its infancy. Market coordination is poor, many market circulation, resulting in volatile market supply and demand instability, resulting in rising costs of aquatic products cold chain logistics.

\subsection{Problem Analysis}

\subsubsection{Lack of Industry Standards}

As China's logistics industry was just emerging, the government's emphasis on the cold chain is still far from sufficient. The standards for the cold chain logistics industry are slow to be established and can't be popularized and popularized [3]. It can be said that there is no sound standard system for cold chain logistics. For example, the logistics industry in the most common tool tray, the current circulation of the tray specifications more messy, according to China's tray Professional Committee tray method specifications, randomly selected four common cold chain logistics companies aquarium tray, spot checks found that the four companies tray specifications shown in Table 1.

In addition, compared with other logistics developed countries, China's logistics industry started relatively late, and the government did not attach great importance to the development of the early period, resulting in our government for the logistics industry, laws and regulations is not perfect, the state for the cold chain lack of effective logistics regulatory system.

\subsubsection{Qiushui Lake Aquatic Products Market Lack of Strong Third Party Logistics Companies}

Qiushui lake aquatic products cold chain logistics in many aspects, there is still no effective convergence mechanism, there is no well-formed cold chain logistics service system, the lack of professional aquatic products cold chain logistics companies. Qiushui Lake cold-chain logistics market, small and medium-sized

Table 1. Tray specifications (unit: $\mathrm{mm}$ ).

\begin{tabular}{ccccc}
\hline Tray Number & B Company & C Company & D Company & E Company \\
\hline 1 & $2000 \times 1000$ & $1300 \times 1000$ & $1100 \times 1000$ & $1000 \times 800$ \\
2 & $1500 \times 1100$ & $1200 \times 1000$ & $1100 \times 1100$ & $1200 \times 1200$ \\
3 & $1500 \times 1000$ & $1200 \times 800$ & $1100 \times 900$ & $1300 \times 1600$ \\
4 & $1400 \times 1200$ & $1200 \times 1100$ & $1000 \times 1000$ & $1300 \times 1100$ \\
\hline
\end{tabular}

Note: The true name of the company is replaced by B, C, D, E and the same pallet size has been omitted. 
companies are the main body of cold chain logistics companies, but these companies generally weak strength, small scale of operation, service standards are not uniform and other shortcomings, service standards are not uniform and other shortcomings, most of them can only provide cold-storage transport services, can't provide the full meaning of the cold chain logistics services, business capability is not strong, with large-scale cold chain logistics resources integration and industry promotion capabilities have not yet formed. Qiushui Lake aquatic products cold chain logistics companies started relatively late, lacking related software and hardware facilities, the service standards are not perfect. Cold chain logistics industry on the capital, technical requirements are high, domestic third-party logistics companies do not have strong economic strength and no smooth and convenient financing channels, it is difficult to promote the rapid development of cold-chain logistics industry.

Similarly, the aquatic products cold chain logistics usually requires advanced equipment and strict management. Farmers tend to entrust aquatic products to third-party logistics companies to market the operation of circulation. However, the lack of core competitive third-party logistics companies in the Aquatic products nowadays. Lack of corresponding industry standards, which caused the small and medium-sized logistics companies malicious price competition, is not conducive to the storage and transportation of Qiushui Lake aquatic products.

\subsubsection{Lack of Professional Logistics Personnel and Information Technology Is Backward}

Because cold chain logistics operation and monitoring involves a variety of disciplines, science, technology and safety of professional features, so most of the cold chain logistics professionals, in addition to need to understand supply chain management, food science and other knowledge, you must also have With frozen technology, refrigeration technology, mechanical technology and other related knowledge background [4]. In Qiushui Lake, people are often bound by the limitations of the education system and the traditional concepts, and people with cold chain logistics management skills are seriously lacking. For A county, the existing number of aquatic product operators is huge, but their professionalism is not high and their professional skills are not strong. Knowledge can't be effectively translated into practice, so they can only engage in relatively simple logistics and distribution work.

In the era of Internet information sharing, the extensive use of the internet for the timely sharing of information has brought convenience, Qiushui Lake aquatic products related websites prevalence of incomplete information, the update rate is slow. Most aquaculture farmers know nothing about internet technologies. Most of their sales channels are towns' bazaars, the best choice is only those local small supermarkets. Most of them are not accustomed to trading aquatic products on the Internet. People are often afraid of the unknown world. The network is the "unknown world" of these farmers. Rarely do they update their aquatic products information online in a timely manner. 


\section{Suggestions on Improvement of Qiushui Lake Aquatic Products Cold Chain Logistics}

Qiushui Lake aquatic products cold chain logistics the most important primary factor advantages-the geographical advantage is congenital (Lake is located in The Beijing-Kowloon Railway and Lanzhou-Lianyungang Railway Interchange, the construction of the Zhengzhou-Xuzhou High-speed Railway will be upgrade Qiushui Lake aquatic products cold chain logistics to a higher level). However, senior elements (mainly network resources, technical resources, human resources, etc.) need to be realized through long-term capital investment and cultivation in the future. Although Qiushui Lake aquatic products cold chain logistics in the near future is difficult to achieve large-scale development of the stride, but the long-term may be to promote Qiushui Lake cold chain logistics development. Therefore, according to the current development status and the problems for the development of Qiushui Lake aquatic products cold chain logistics, this article proposes the following suggestions:

\subsection{The Improvement of Relevant Laws, Regulations and Industry Standards}

Cold chain logistics including aquatic products production and processing, storage, transportation, distribution, sales and etc. Logistics companies only specification to ensure the steady operation of cold chain logistics and the smooth operation of the whole chain.

The relevant government departments should formulate and improve the relevant standards of the aquatic products cold chain logistics as soon as possible, actively guide and supervise the logistics companies in accordance with the relevant standards: 1) the standards implementation of cold chain logistics aspects: the government needs to send special personnel to use the ways such as questionnaire or on-site interview, actively collecting and seek the actual needs of companies and consumers, the real effective implementation of the standards. 2) to guide the supervision: the government should strengthen the construction of the aquatic products cold chain supervision system, and adopt the supporting policies and laws and regulations as soon as possible, ensure the enforcement of standards, and make use of various communication tools to promote the promotion of cold chain standards.

At present, the county government has increased the construction and normative strength of the cold chain of aquatic products from the aspects of refrigerated trucks and cold chain logistics, and has broken up many standard and irregular logistics companies. The relevant standards are also being worked out.

\subsection{Accelerate the Development of Third-Party Aquatic Products Cold Chain Logistics Companies}

Because of the characteristics of aquatic products and the high cost of infrastructure investment in cold chain logistics and the long capital recovery period, 
the traditional self-supporting logistics model can't adapt to the development requirements of the current or future aquatic products cold chain logistics [5]. The specialized, large-scale and organized third-party cold chain logistics is the trend of the future cold chain market development. Through mergers, joint ventures, joint and other ways to integrate cold chain logistics resources, we will cultivate and develop a large number of large-scale third-party cold-chain logistics companies with great development potential, advanced management concepts and management methods, and strong ability of radiating power. To improve the integrated fresh food cold chain logistics system to realize the "multiple wins" of farmers, service providers, producers and sellers. Through policy support to strengthen the fiscal, taxation and other multi-directional and comprehensive support policies to foster a group of third-party logistics companies with strong economic strength and core competitiveness. The company will encourage the production companies of aquatic products to realize cold chain control from fishing to sales, increase the development intensity of cold-chain logistics transportation and low-temperature distribution of aquatic products, and establish a cold chain logistics system with the core of water products cold chain logistics companies [6].

In addition, A county government should vigorously develop the professional third-party logistics companies, encourage local large supermarkets such as Oriental supermarkets, WanJiale supermarkets, and 68 supermarkets to provide third-party cold chain logistics services, promote the "aquatic products supermarket docking" cold chain logistics mode, and actively cultivate the third-party aquatic products cold chain logistics company with certain core competitiveness and business scale to enter the market of Qiushui Lake products. The refrigerated vehicles provided by third party logistics companies must adopt advanced refrigeration and refrigeration technology to better retain the freshness of aquatic products and adopt centralized collection transportation, which can reduce the transportation and distribution cost of each aquatic product enterprise, thus reducing the cost of the whole aquatic product cold chain transportation link. Meanwhile, Global positioning system (GPS) technology is used in refrigerated vehicles for real-time monitoring of the state of aquatic products.

\subsection{Training and the Introduction of Logistics Professional and to Establish a Comprehensive Information Platform}

So far, there's a shortage of cold chain logistics professional, including Research and development personnel, manager, operators, information manager, etc. The product manufacturer of Qiushui Lake has the phenomenon of heavy use and light cultivation for the staff of the enterprise. The lack of professionals has seriously restricted the development of cold chain logistics. It is imperative to cultivate the cold chain logistics Professional of aquatic products. In order to solve the problem of shortage of professional cold-chain logistics Professional, the market of Qiushui Lake products should be solved through the introduction of cold-chain logistics Professional and professional skills training of cold chain 
logistics, so as to train the actual operators of cold chain logistics. To promote cold-chain logistics companies to adopt the methods of entrustment, order cultivation, jointly with the professional education institution and technical secondary school of cold chain logistics. The school provides the professional cold chain logistics Professional for the enterprise, the enterprise provides the training base for colleges and universities, jointly implements the vocational training and continues education, training the skilled and intelligent Professional, and provides long-term motivation for the development of cold chain logistics.

In view of the lack of information sharing and the "fear" of aquatic products farmers on the Internet, it can be solved in several ways: 1) An information sharing platform of Qiushui Lake product can be opened on the website of the water conservancy bureau of A county. The water resources bureau can send the commissioner to carry out an effective tracking of the water product quality production and daily production activities of Qiushui Lake, and then timely update the tracking on the website of the bureau of water resources. 2) Government organizes aquatic products farmers to jointly build a website platform for the sales website of Qiushui Lake products, and hires professionals to carry out daily maintenance of the website and timely update of aquatic product information.

\section{Conclusion}

Through the research of this paper, it provides a theoretical basis and technical support for the development of Qiushui Lake aquatic products cold chain logistics. From a fundamental solution to the Qiushui Lake aquatic products, cold chain logistics exists lack of efficient institutional mechanisms and standard industry standards, lack of effective institutional mechanisms and standard industry standards, lack of logistics Professional who will integrate professional knowledge skills with the market and other issues. However, during the research process, some specific laws and regulations are not thoroughly studied, and Qiushui Lake aquatic product market layout lack of detailed research. In this paper, these deficiencies will be improved in the following research. We believe that there will be a significant development in Qiushui Lake aquatic products cold chain logistics industry.

\section{References}

[1] Gong, M. and Gao, H. (2013) China's Aquatic Products Cold Chain Logistics Optimization Problem. Shopping Modernization, No. 28, 5-6.

[2] Yi, B. (2014) Fruit and Vegetable Cold Chain Logistics Economic Opportunity Analysis. Modern Commerce Industry, No. 1, 19-21.

[3] Li, S.Z. (2016) Jingzhou City, Cold Chain Logistics Development of Aquatic Products Research Path. Logistics Technology, No. 21, 35-36.

[4] Wang, J.C. (2013) Dalian Aquatic Products Cold Chain Logistics Problems and Countermeasures Analysis. Business Era, No. 8, 28-29.

[5] Liang, Y. (2016) Study on the Development of Cold Chain Logistics in China Based 
on SWOT Analysis. Logistics Science and Technology, No. 2, 13-14.

[6] Zhu, C.C. (2011) Study on Cold Chain Logistics System of Chinese Agricultural Products. Journal of Anhui Agricultural Sciences, No. 4, 67-72. 